\title{
Fault Prediction of Elevator Door System Based on PSO-BP Neural Network
}

\author{
Penggao Wen, Meng Zhi, Guangyao Zhang, Shengmao Li \\ Chongqing Special Equipment Inspection and Research Institute, Chongqing, China \\ Email:wpg1018@163.com
}

How to cite this paper: Wen, P.G., Zhi, M., Zhang, G.Y. and Li, S.M. (2016) Fault Prediction of Elevator Door System Based on PSO-BP Neural Network. Engineering, 8, 761-766.

http://dx.doi.org/10.4236/eng.2016.811068

Received: September 28, 2016

Accepted: October 28, 2016

Published: October 31, 2016

Copyright $\odot 2016$ by authors and Scientific Research Publishing Inc. This work is licensed under the Creative Commons Attribution International License (CC BY 4.0).

http://creativecommons.org/licenses/by/4.0/

\begin{abstract}
Nowadays, the elevator has become an indispensable means of indoor transportation in people's life, but in recent years this kind of traffic tools has caused many casualties because of the gate system fault. In order to ensure the safe and reliable operation of the elevator, the failure of elevator door system was predicted in this paper. Against the fault type of elevator door system: elevator door opened, excessive vibration when elevator door opened or closed, elevator door did not open or closed when reached the specified level. Three fault types were used as the output of the prediction model. There were 8 reasons for the failure, used them as input. A model based on particle swarm optimization (PSO) and BP neural network was established, using MATLAB to emulation; the results showed that: PSO-BP neural network algorithm was feasible in the fault prediction of the elevator door system.
\end{abstract}

\section{Keywords}

Elevator Door System, Gate System Fault, Fault Prediction, PSO-BP Neural Network

\section{Introduction}

Nowadays, the elevator has become an indispensable means of indoor transportation in people's life. Up to 2011, more than 1.2 million elevators were used in our country. Elevator, as a special equipment, cannot be updated frequently. With the increase of the elevator use, the elevator fault occurs more and more often. Among the common casualty accidents occurred in elevator operation process, the door system failure caused by accidents accounted for more than $70 \%$ [1]. Therefore, the elevator door system failure prediction, and timely failure type analysis, can effectively reduce the occurrence of the fault and also reduce the accident caused by the gate system failure.

Online monitoring of the elevator door system in paper [2], by detecting the door 
system during elevator operation process, to a certain extent, can monitor the abnormality of door system, but it cannot judge the type of failure in time; it needs to be improved. The paper [3] analyzed the causes of various faults through established elevator door system fault tree. It can only be used in elevator door system design, but it cannot predict the fault. The control system design of the door system is carried out by DSP in paper [4]. It controlled the probability of occurrence of failure in design process by using the powerful data processing capabilities of DSP, but it cannot predict the occurrence of failure. In paper [5], it predicted the fault of door system based on neural network, because the initialization of the weights and thresholds was randomly generated in BP neural network, so it produced large errors in prediction results.

In this paper, the particle swarm optimization algorithm and BP neural network were used to predict the failure of the gate system; global optimization is based on particle swarm optimization algorithm to find the appropriate weights and thresholds, using them in BP neural network, to avoid the error of weights and thresholds occurring randomly in $\mathrm{BP}$ neural network. By comparing with the single $\mathrm{BP}$ neural network, the PSO-BP neural network is more accurate in the fault prediction of the elevator door system.

\section{The Structure of Elevator Door System}

\subsection{The Composition of the Mechanical System of Elevator Door System}

The elevator door system is usually composed by door leaf, door roller, door shoe, door sill, door hanger rail etc. The car door is hang on the guide way through the door roller, door shoe coordinate with car door sill at substructure; the landing door is hang on the guide way through the door roller, door shoe coordinate with sill at substructure; electric and mechanical interlocking device installed in hoist way door.

\subsection{The Composition of Electrical System of Elevator Landing Door}

There are many kinds of electrical system in the elevator landing door, the control method is also complicated. Generally speaking, the landing door is composed of controller, driving device, mechanical device, door opening and closing limit and a door access protection device etc. This system is easy to malfunction in elevator operation; it will lead to elevator fault because of system failure.

\subsection{Elevator Door System Fault and Fault Signal Acquisition}

The common faults of elevator door system include the elevator cannot be closed or open; the elevator door is not open after reaching the designated floor; when press the close button, the elevator door closed, but it cannot start; the door is opened but the elevator can choose to start; the door open or close speed turns slow; excessive vibration when elevator door opened and closed, etc. These failures are mainly caused by the abnormality of the components in the mechanical parts of the elevator or the electric control system. In order to collect the fault signal, the faults is converted to the required electrical signal by the detection device. 


\section{Construction of PSO-BP Neural Network Model}

\subsection{BP Neural Network}

BP neural network (Back-propagation Neutral Network) is a multi layer feed forward neural network based on error back propagation algorithm (BP algorithm), the learning process concludes two processes: positive signal propagation and error back-propagation [6]. When signal is forward propagated, the input samples are introduced from the input layer then transfer to the output layer through hidden layer process layer by layer, it will transfer to error back propagation phase if the actual output of the output layer is not in conformity with the desired output (supervision signal), then turns to error back-propagation; error back-propagation means pass the output error in some form through input layer to output layer back propagation and allocate to error to all the units of each layer to obtain the error signal of each layer, this error signal is used as basis for correction weight of each unit [7].

The performance of network is influenced by the node number in hidden layer [8], the theoretical circles have not been very successful to determine the node number in hidden layer, it usually judged by empirical formula, the formula is $a=\sqrt{m+n}+\alpha$, in this formula , N, m represent the input, the output layer node number respectively, constant $\alpha=1$ - 10 [9]. BP neural network topology is shown in Figure 1.

\subsection{Construction of PSO-BP Model}

The advantages of Particle Swam Optimization are operating easily, few parameters, convergence fast, easy to implement and so in, so the PSO received many researchers' attention and developed rapidly and is widely used in the fields of artificial intelligence, neural network, control theory, function optimization [10]. When using BP neutral network to predict, weights and thresholds initial randomly, to a certain extent, it will bring a great impact on the outcome of the forecast. The weights and thresholds are not

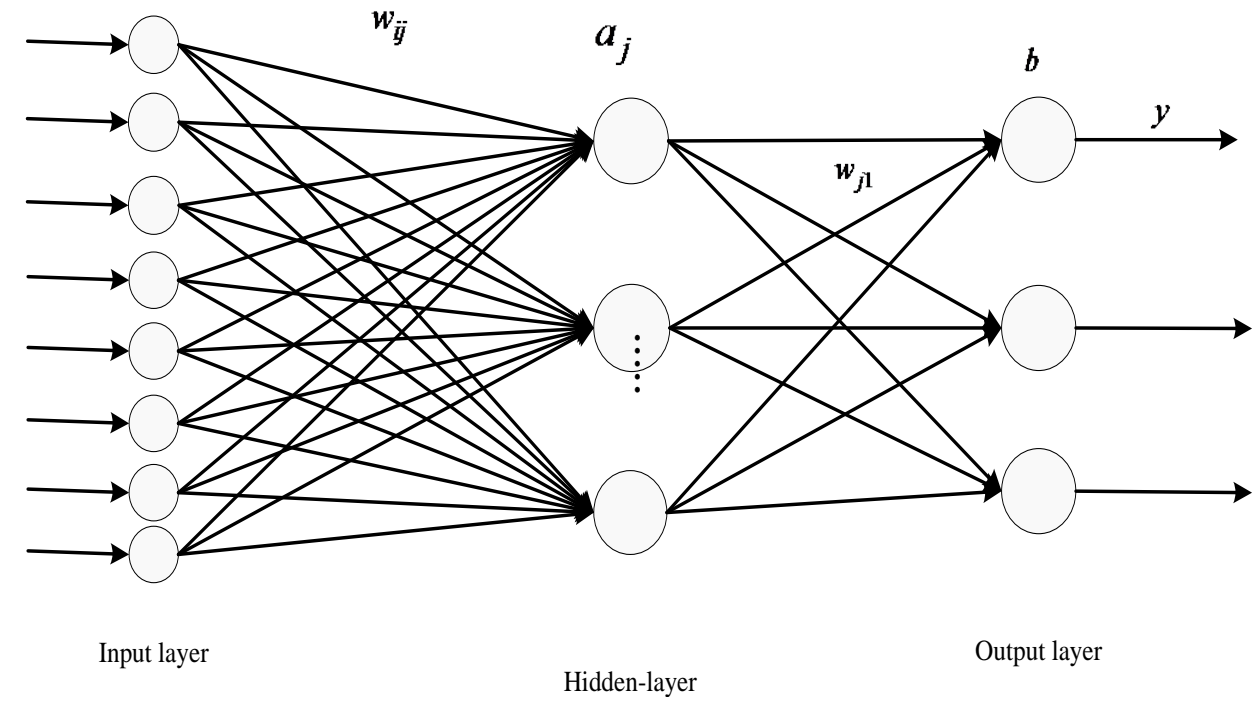

Figure 1. BP neural network topology. 
randomly initialized through $\mathrm{PSO}-\mathrm{BP}$, it can improve the accuracy of the prediction model. PSO-BP flow chart is shown in Figure 2.

\section{Failure Prediction and Analysis of Elevator Door System}

Choose the common door system fault to predict, the three door system faults are: 1 the door is opened, the elevator can choose to start; 2 the door vibrate terribly when opened or closed; 3 the door cannot be closed or opened. We named these three failures are $y_{1}, y_{2}, y_{3}$, and set them as the output of PSO-BP neural network. Input is the reason for the three kinds of fault: switch contact of door lock is adhered $\left(\mathrm{X}_{1}\right)$ the fuse of control circuit is loose $\left(\mathrm{X}_{2}\right)$, the deformity or slight tilt of door guide rail $\left(\mathrm{X}_{3}\right)$ slip when gate machine drive $\left(\mathrm{X}_{4}\right)$ the relay of door lock has been grip $\left(\mathrm{X}_{5}\right)$ the dust heaped in sliding chute of sill $\left(\mathrm{X}_{6}\right)$ resistance of the door machine is broken $\left(\mathrm{X}_{7}\right)$ the door pulley wear seriously $\left(\mathrm{X}_{8}\right)$, in raw data, when the value of $\mathrm{y} 1, \mathrm{y} 2, \mathrm{y} 3$ is 1 , at this time there will be a corresponding fault. The reason and the type of faults during operation of door system are shown in Table 1.

From the table, there are 8 neurons in input layer and 3 neurons in output layer of BP neural network, the range of neurons' number in input layer is 5 - 14, the range is calculated from the formula above, choose 12 neurons number through simulate in this paper. Choose hyperbolic tangent function as transfer function, the network training number is 500 , the training error is 0.001 . Set three groups of data as training group,

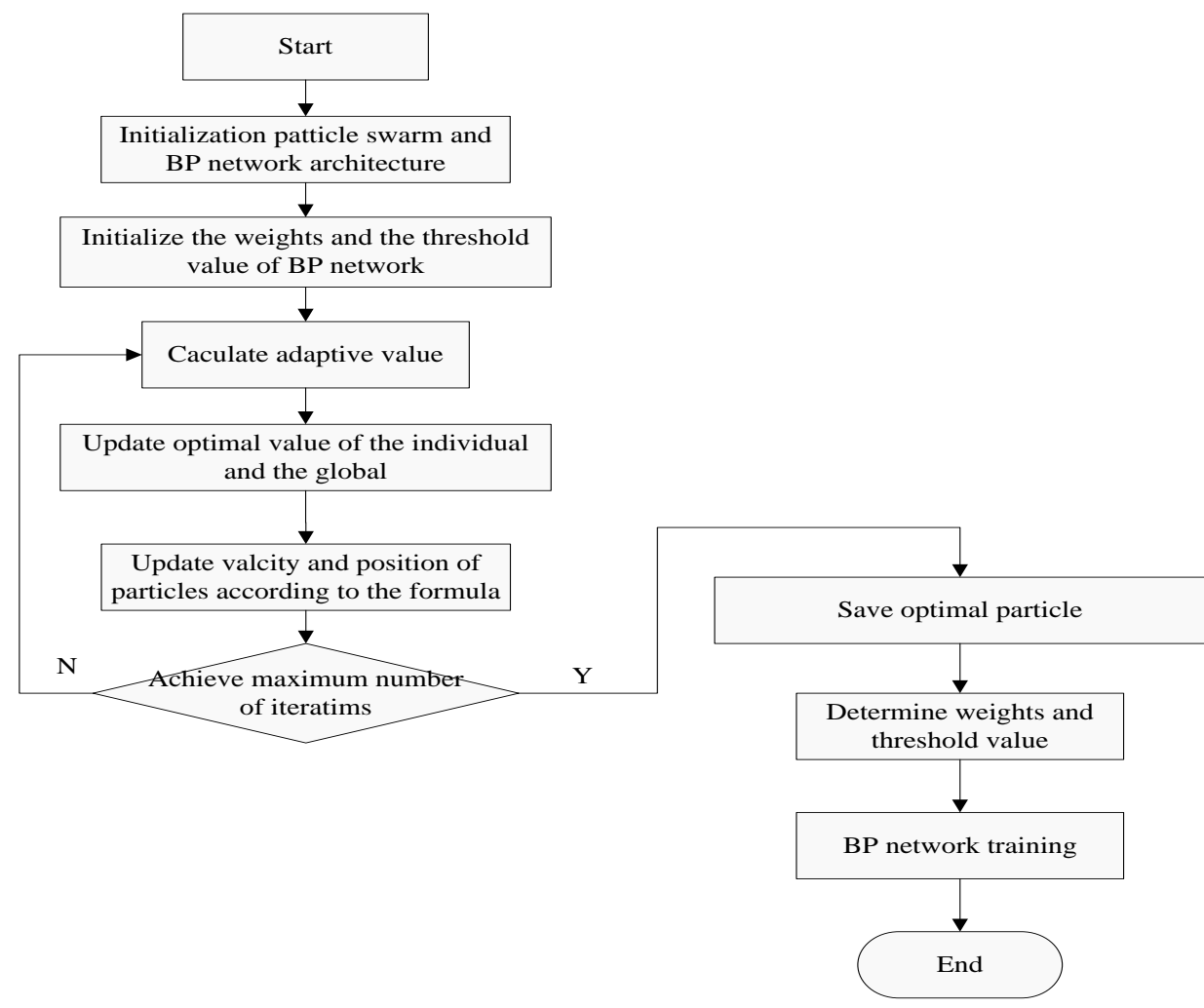

Figure 2. PSO-BP flow chart. 
Table 1. The reason and the type of fault during operation of door system.

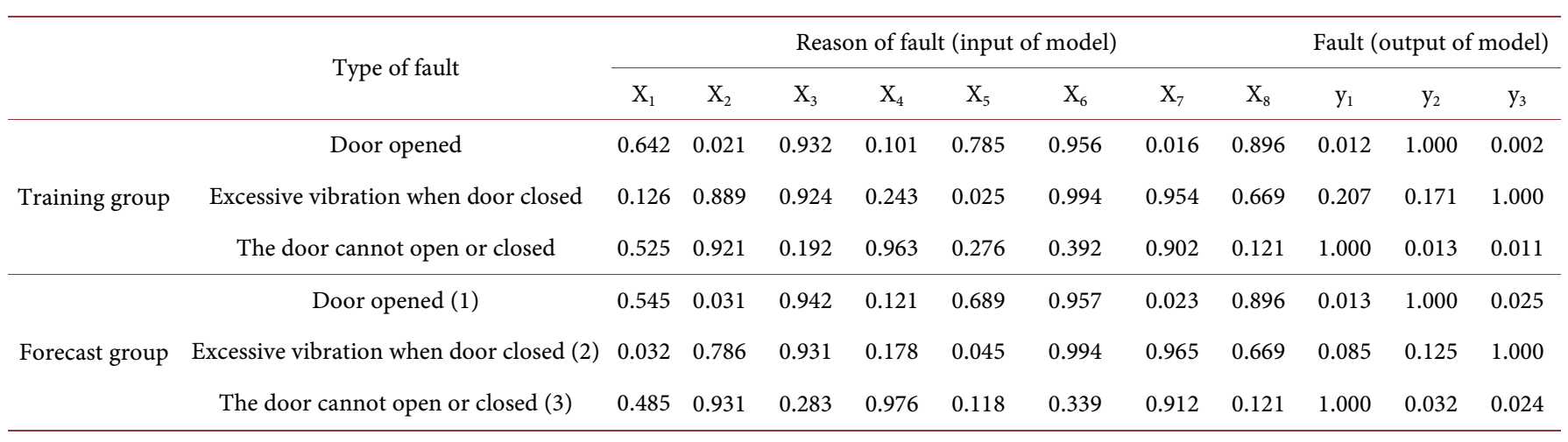

Table 2. Fault prediction of elevator door system through PSO-BP neural network.

\begin{tabular}{|c|c|c|c|c|c|c|c|c|c|c|c|}
\hline Samples & \multicolumn{8}{|c|}{ Reason of fault (input of model) } & \multicolumn{3}{|c|}{ Fault (output of model) } \\
\hline 1 & 0.545 & 0.031 & 0.942 & 0.121 & 0.689 & 0.957 & 0.023 & 0.896 & 0.033 & 0.972 & 0.041 \\
\hline 2 & 0.032 & 0.786 & 0.931 & 0.178 & 0.045 & 0.994 & 0.965 & 0.669 & 0.097 & 0.115 & 0.968 \\
\hline 3 & 0.485 & 0.931 & 0.283 & 0.976 & 0.118 & 0.339 & 0.912 & 0.121 & 0.970 & 0.063 & 0.046 \\
\hline
\end{tabular}

Table 3. Fault prediction of elevator door system through BP neural network.

\begin{tabular}{|c|c|c|c|c|c|c|c|c|c|c|c|}
\hline Samples & \multicolumn{8}{|c|}{ Reason of fault (input of model) } & \multicolumn{3}{|c|}{ Fault (output of model) } \\
\hline 1 & 0.545 & 0.031 & 0.942 & 0.121 & 0.689 & 0.957 & 0.023 & 0.884 & 0.021 & 0.923 & 0.045 \\
\hline 2 & 0.032 & 0.786 & 0.931 & 0.178 & 0.045 & 0.994 & 0.965 & 0.689 & 0.086 & 0.056 & 0.909 \\
\hline 3 & 0.485 & 0.931 & 0.283 & 0.976 & 0.118 & 0.339 & 0.912 & 0.144 & 0.891 & 0.025 & 0.088 \\
\hline
\end{tabular}

the three samples set as prediction group. And the three fault type are: Elevator door open, excessive vibration when elevator door open, elevator door cannot open or close. In this experiment, the parameters of PSO-BP are: Population size $M=50$, the maximum number of iterations $G=200$, the number of input nodes is 8 , the number of output nodes is 3 , and total weights are $8 \times 12+12 \times 3=132$, the threshold number are 15 , the search spatial dimension are $\mathrm{N}=132+15=147$, build 8-12-3 structure of BP network. Set three groups of data as training group and also set three kinds of data as prediction group to simulate through PSO-BP. The simulation data are shown in Table 2. The fault prediction of elevator door system through BP neural network shows in Table 3.

From the data in Table 2, when the data value is close to 1, it means that the possibility of fault occur at this time is increase, when value of the other two data is relatively small, it means that possibility of fault occur at this time is very small, From a statistical point of view, random occurrence of small probability events will not occur. Thus, the fault type predicted by sample 1, 2, 3, in table are: Elevator door open, excessive vibra- 
tion when elevator door open, elevator door cannot open or close, these are matched the fault type which original data displayed.

\section{Conclusion}

This paper is focused on the application of PSO-BP neural network algorithm in fault prediction of the elevator door system, by applying the PSO algorithm to the BP algorithm. It recovered the weakness about BP algorithm need to initialize the weights and thresholds. Through simulation by MATLAB, it shows that using PSO-BP neural network algorithm to establish the model is very effective to solve problem of fault prediction during elevator door system operation.

\section{References}

[1] Lin, D.Y. (2012) Failure Cause Analysis and Prevention Measures in the Elevator Door System. Friend of Science Amateurs, 7, 19-20.

[2] Zhen, S.J. (2009) State Monitor and Experimental Research of Elevator Door System. Shanghai Jiao Tong University, Shanghai.

[3] Xue, T., Peng, Q.F., Huang, G.J., et al. (2015) Fault Analysis and Evaluation Method of Elevator Door System Based on Fault Tree. Automation \& Information Engineering, 6, 34-36.

[4] Zhai, Z.Z. (2015) DSP-Controlled Elevator Door-Motor System. Guangdong University of Technology, Guangzhou.

[5] Li, J.F., Qu, Z.W., Dou, L.Q., et al. (2009) Study of the Fault Predication for Elevator Gate System Based on Neural Network. Journal of Tianjin University of Technology, 1, 8-10.

[6] Shao, Y.X., Chen, Q. and Zhang, D.M. (2008) The Application of Improved BP Neural Network Algorithm in Lithology Recognition. Lecture Notes in Computer Science, 5370, 342-349. http://dx.doi.org/10.1007/978-3-540-92137-0_38

[7] Ince, D. and Sofu, A. (2013) Estimation of Lactation Milk Yield of Awassi Sheep with Artificial Neural Network Modeling. Small Ruminant Research, 1.

[8] Lu, Q.S. and Wang, S.Q. (2011) BP Neural Network Optimization Algorithm Based on Genetic-Stimulated Annealing. Computer and Modernization, 6, 91-94.

[9] Yuan, C.R. (1999) Artificial Neural Network and Application. Tsinghua University Press, Beijing.

[10] Poli, R., Kennedy, J. and Blackwell, T. (2007) Particle Swarm Optimization. Swarm Intelligence, 1, 33-57. http://dx.doi.org/10.1007/s11721-007-0002-0 
Submit or recommend next manuscript to SCIRP and we will provide best service for you:

Accepting pre-submission inquiries through Email, Facebook, LinkedIn, Twitter, etc. A wide selection of journals (inclusive of 9 subjects, more than 200 journals)

Providing 24-hour high-quality service

User-friendly online submission system

Fair and swift peer-review system

Efficient typesetting and proofreading procedure

Display of the result of downloads and visits, as well as the number of cited articles

Maximum dissemination of your research work

Submit your manuscript at: http://papersubmission.scirp.org/

Or contact eng@scirp.org 